NBER WORKING PAPER SERIES

\title{
STOCK MARKET AND INVESTMENT GOODS PRICES: IMPLICATIONS FOR MACROECONOMICS
}

\author{
Lawrence J. Christiano \\ Jonas D. M. Fisher \\ Working Paper 10031 \\ http://www.nber.org/papers/w10031
NATIONAL BUREAU OF ECONOMIC RESEARCH
1050 Massachusetts Avenue
Cambridge, MA 02138
October 2003

This is a revision of Chicago Fed working paper 98-15. It also supercedes 'Tobin's q and Asset Returns: Implications for the Business Cycle,' which appeared as NBER working paper 5292. We thank Gadi Barlevy, Michele Boldrin, Marty Eichenbaum, Lars Hansen and an anomymous referee for advice. The views expressed herein are those of the authors and not necessarily those of the Federal Reserve Bank of Chicago, the Federal Reserve System, or the National Bureau of Economic Research.

(C)2003 by Lawrence J. Christiano and Jonas D. M. Fisher. All rights reserved. Short sections of text, not to exceed two paragraphs, may be quoted without explicit permission provided that full credit, including (C) notice, is given to the source. 
Stock Market and Investment Goods Prices: Implications for Macroeconomics

Lawrence J. Christiano and Jonas D. M. Fisher

NBER Working Paper No. 10031

October 2003

JEL No. E10, E32

\section{ABSTRACT}

Stock market prices, a measure of the marginal cost of installed capital, are procyclical. Yet, prices of investment goods, the main input into new installed capital, are countercyclical. We exploit this information to identify the driving forces of the business cycle and the nature of capital installation costs. In our model installation costs are increasing in the growth of investment, and the business cycle is driven by permanent investment-specific technology shocks and transitory neutral technology shocks. When calibrated to the capital price observations, the model does well at accounting for the main features of asset returns and the business cycle of macroeconomic aggregates. In addition, unlike most other models, our's accounts for sectoral comovement in both output and factor inputs.

Lawrence J. Christiano

Department of Economics

Northwestern University

2003 Sheridan Road

Evanston, IL 60208

and NBER

1-christiano@northwestern.edu

Jonas D. M. Fisher

Research Department

Federal Reserve Bank of Chicago

230 South LaSalle Street

Chicago, IL 60604

jfisher@frbchi.org 


\section{Introduction}

Stock market prices, a measure of the marginal value of installed capital, are procyclical. Yet, prices of investment goods, the main input into new installed capital, are countercyclical. ${ }^{1}$ We exploit this information to identify the driving forces of the business cycle and the nature of capital installation costs. In our model, installation costs are increasing in the growth of investment, and the business cycle is driven by permanent investment-specific technology shocks and transitory neutral technology shocks. When calibrated to the price observations, our model does well at accounting for the main features of asset returns and the business cycle.

To understand how our model accounts for the dynamics of capital prices, it is helpful to recall a basic property of neoclassical models, that the price of a firm's stock equals the marginal cost of its installed capital. The investment-specific shocks play a small role because they trigger offsetting effects on marginal installation costs. The fall in investment prices after a positive investment-specific shock pushes marginal cost down, while the rise in investment works in the other direction, by increasing installation costs. Our finding that the latter effect is relatively small explains our conclusion that stock prices are countercyclical relative to investment-specific shocks. The marginal cost of installed capital responds strongly and procyclically to a neutral shock because this increases the demand for investment goods which causes the two effects just cited now to work in the same direction. Therefore, stock prices are procyclical because they are dominated by the neutral shock. Similar to Greenwood, Hercowitz and Krusell (2000) (GHK), investment good prices are countercyclical because they are dominated by the investment-specific shock.

The phenomena that interest us lie at the intersection of macroeconomics and finance. To have confidence in the inferences we draw from the data, we need to be sure that they are not inconsistent with the salient facts in these two areas. For example, since the procyclicality

\footnotetext{
${ }^{1}$ The procylical nature of stock prices is well known. For documentation, see Christiano and Fisher (1995) and Fischer and Merton (1984) and the references they cite. The cyclical behavior of investment good prices is documented in Greenwood, Hercowitz and Krusell (1997, 2000), Murphy, Shleifer and Vishny (1989), Christiano and Fisher (1997) and Fisher (2003).
} 
of equity prices is a feature of asset prices, it is particularly important to verify that our explanation does not conflict with existing explanations of other features of asset markets. Similarly, since our focus is on characteristics of the business cycle, we want to verify that our hypothesis is not at odds with the business cycle facts.

These considerations lead us to work with a modification of the model of Boldrin, Christiano and Fisher (2001) (BCF). Their model incorporates assumptions designed to help account for basic features of asset returns, and represents a step forward compared to standard business cycle models in accounting for the business cycle. Nevertheless, it has the property that stock market and investment good prices are both strongly procyclical. When we introduce our modifications, the asset pricing implications are comparable to those of $\mathrm{BCF}$ and the improved business cycle implications of that model are retained. Moreover, our model improves on a notable drawback of the BCF model, that investment in the consumption sector is counter-cyclical. In our model, output and both factor inputs display the sectoral co-movement phenomenon.

The empirical success of the model lends credibility to the interpretation of the business cycle it describes. Therefore the technology shock driven business cycle hypothesis is supported by the findings. However, the nature of the technology process underlying our findings is quite different from that typically assumed. In addition to involving both neutral and investment-specific shocks, we find that these shocks must be highly correlated to account for the data. So while the nature of the process is different, the conclusion that there is a single major technological source for the business cycle is the same.

The paper is organized as follows. Section 2 presents our model. Section 3 discusses our strategy for assigning values to the model's parameters and Section 4 evaluates our calibrated model's empirical implications. Section 5 discusses some potential alternative explanations for the capital price dynamics and Section 6 concludes. 


\section{The Model Economy}

There are two sets of assumptions that differentiate our model from a standard one-sector, representative agent real business cycle model. First, we adopt the assumptions proposed in $\mathrm{BCF}$ to account for asset returns: preferences have the habit persistence form proposed in Constantinides (1990) and Sundaresan (1989); investment and consumption goods are produced in spatially isolated industries; and the allocation of capital and labor to sectors must be made prior to the realization of the current period technology shocks. The assumptions on preferences result in procyclical demand for productive capital. The assumptions on technology guarantee that the supply of capital is inelastic in the short run. BCF show that the combined effects of these two features produce a cyclical pattern in capital gains that allows a model with neutral technology shocks to generate a large equity premium. Second, we adopt modifications designed to help the model account for the dynamic behavior of stock market and investment good prices: a transitory technology shock perturbs both production technologies; the investment good technology is also perturbed by a permanent shock; and there are costs associated with the installation of new investment goods.

\subsection{Preferences}

The preferences of the representative agent are:

$$
E_{0} \sum_{t=0}^{\infty} \beta^{t}\left[\log \left(C_{t}-b C_{t-1}\right)-H_{t}\right], 0<\beta<1, b \geq 0
$$

where, $0<C_{t}$ denotes time $t$ consumption, $0 \leq H_{t}$ denotes time $t$ labor, and $E_{0}$ is the conditional expectation operator. When $b>0$ household preferences are characterized by habit persistence. When $b=0$, these preferences correspond to those in a standard RBC model. See BCF for a discussion of the use of habit persistence in macroeconomics. 


\subsection{Technology}

The technology for producing consumption goods in $t$ is

$$
C_{t} \leq Z_{t} K_{c, t}^{\alpha_{c}} H_{c, t}^{1-\alpha_{c}}, \quad 0<\alpha_{c}<1
$$

where $Z_{t}=\exp \left(\theta_{t}\right)(1+\gamma)^{t}$ is the neutral technology, with $\gamma \geq 0$ the growth rate of this technology and $\theta_{t}$ a covariance stationary shock:

$$
\theta_{t}=\rho \theta_{t-1}+\varepsilon_{t}, \quad 0<\rho<1 .
$$

The technology for producing new investment goods in $t$ is

$$
I_{c, t}+I_{i, t} \leq Z_{t} V_{t} K_{i, t}^{\alpha_{i}} H_{i, t}{ }^{1-\alpha_{i}} \quad 0<\alpha_{i}<1
$$

where

$$
V_{t}=\exp \left(\mu+\nu_{t}\right) V_{t-1}
$$

Here, $K_{c, t}$ and $K_{i, t}$ denote the beginning of period stocks of capital in the consumption and investment sectors. Similarly, $H_{c, t}$ and $H_{i, t}$ refer to hours worked in the consumption and investment good sectors, with $H_{t}=H_{c, t}+H_{i, t}$. The term $V_{t}$ is the investment-specifc technology with $\mu \geq 0$ denoting the mean growth rate of this techology. Greenwood, Hercowitz and Krusell (1997) argue that investment specific technical change is a more important source of growth than growth in the neutral technology. This strongly suggests it is also important for the business cycle. The innovations $\varepsilon_{t}$ and $\nu_{t}$ in (3) and (5) are independent of time, zero-mean, normally distributed random variables with standard deviations $\sigma_{\varepsilon}$ and $\sigma_{\nu}$ and contemporaneous correlation coefficient $\omega$.

Our dual technology shock specification has not been considered much. It is common to assume a single stationary neutral shock. Relatively few papers have considered investmentspecific shocks. Business cycle models that include this kind of shock have been studied by Campbell (1998), Fisher (1997), Greenwood, Hercowitz and Huffman (1988), and GHK. 
GHK describe a model with dual technology shocks, but they assume both shocks are transitory and they do not consider the possibility that two shocks are correlated.

Our assumption that the business cycle is driven mostly by an investment-specific shock that is permanent and a neutral shock that is transitory is not at odds with the recent macro-econometric literature. Christiano, Eichenbaum and Vigfusson (2003), Gali (1999) and Fisher (2003) document, in a quite general way, that permanent neutral shocks are unimportant for the business cycle. However, the methodology underlying these papers leaves open the possibility that orthogonal transitory neutral shocks have a role to play in the business cycle. Fisher (2003) also finds a permanent component in aggregate investment good prices and estimates that shocks to this account for a large fraction of the business cycle. This estimate does not depend on assuming the shock is orthogonal to a transitory neutral shock. ${ }^{2}$

The technology for producing end of period $t$ capital $K_{x, t+1}$, for sector $x$ is

$$
K_{x, t+1} \leq(1-\delta) K_{x, t}+F\left(I_{x, t}, I_{x, t-1}\right)
$$

where

$$
F(x, y)=\left(1-G\left(\frac{x}{\zeta y}\right)\right) x
$$

is the technology for installing new capital. Here, $\zeta$ is the growth rate of investment along a nonstochastic growth path. Following Christiano, et. al. (2003) we restrict the function, $G$, to satisfy the following properties: $G(1)=G^{\prime}(1)=0$, and $\psi \equiv G^{\prime \prime}(1)>0$, where "'s denote differentiation. Under our assumptions, the derivatives of $F$ with respect to its first and second arguments are unity and zero when evaluated in a nonstochastic steady state in both sectors. Because of this, steady state values of quantities and prices in the model are not a function of the adjustment cost parameter, $\psi$. Of course, the dynamics of the model are influenced by $\psi$. When $\psi=0$ the model is equivalent to one without adjustment costs. ${ }^{3}$

\footnotetext{
${ }^{2}$ Once can see this by studying the instrumental variables description of the identification strategy in Fisher (2003).

${ }^{3}$ The model with $\psi=0$, no investment-specific shock and a permanent neutral shock is identical to the
} 
Given our solution procedure, no other features of the $G$ function need to be specified.

The function $F$ penalizes changes in investment growth and not changes in the investment rate, as is conventional in the real business cycle and $q$-theory literatures. Our model incorporates the rate case if we assume the second argument of $F$ is $K_{x, t}$. We use the specification in (6) for two main reasons. First, as stressed in BCF, the traditional rate specification is a force for smooth and countercyclical hours worked, both major drawbacks for a technology-shock driven business cycle model. Second, Christiano, et. al. (2003) argue that the growth specification is useful for understanding the consequences of a monetary disturbance because it generates hump shaped responses of output, hours and investment. That paper has a more detailed comparison of the two cost of adjustment specifications.

We assume that $H_{t}, H_{c, t}$ and $H_{i, t}$ are determined prior to the realization of $x_{t}$. This is our way of capturing the notion that it is difficult to quickly adjust aggregate employment and its sectoral allocation in response to a shock. We also assume that capital, once installed in a sector, cannot be shifted to another sector. That is, we assume that $K_{c, t+1}$ and $K_{i, t+1}$ are determined as a function of date $t$ state variables, and cannot be adjusted in response to contemporaneous innovations in technology.

\subsection{Equilibrium}

We find the equilibrium allocations by solving the following planning problem: maximize (1) subject to (2)-(7), $K_{c, t}, K_{i, t}, H_{c, t}, H_{i, t} \geq 0$, the timing assumptions mentioned at the end of the previous section, and $C_{-1}, K_{c, 0}, K_{i, 0}, H_{c, 0}, H_{i, 0}>0$ given. We approximate the solution to the planning problem using the linear approximation strategy of Christiano (1998). It is well understood how to decentralize the allocations that solve the planner's problem by means of competitive markets, and so we do not discuss the details here.

Prices and rates of return are derived from the solution to the planning problem as follows. In this model, the rates of return on equity may differ between the two sectors. The rate of return on equity in sector $x=c, i$ is:

model in BCF. 


$$
1+r_{x, t+1}^{e}=\left(1+d_{t}^{x}\right)\left[\frac{m p k_{x, t+1}+(1-\delta) P_{k_{x}, t+1}}{P_{k_{x}^{\prime}, t}}\right]-d_{t}^{x}\left(1+r_{t}^{f}\right),
$$

where $m p k_{x, t+1}$ denotes the marginal product of capital in sector $x$, denoted in period $t+1$ consumption units. The variable $d_{t}^{x}$ denotes the firm's debt to equity ratio. As is well known, $d_{t}^{x}$ is not determined in equilibrium, although the equilibrium quantity allocations in the model are unique and coincide with the allocations that emerge from the planning problem. In practice, we set $d_{t}^{x}$ equal to a constant, $d$, denoting the average debt to equity ratio in the economy. Finally, the risk-free rate of return, $r_{t}^{f}$, is computed using

$$
r_{t}^{f}=\frac{\Lambda_{c, t}}{\beta E_{t} \Lambda_{c, t+1}}-1
$$

where $\Lambda_{c, t}$ is the Lagrange multiplier on (2) in the planner's problem.

The overall return on equity, $r_{t+1}^{e}$, is:

$$
r_{t+1}^{e}=\frac{P_{k_{c}^{\prime}, t} K_{c, t+1}}{K_{t+1}} r_{c, t+1}^{e}+\frac{P_{k_{i}^{\prime}, t} K_{i, t+1}}{K_{t+1}} r_{i, t+1}^{e}
$$

where $K_{t+1}=P_{k_{c}^{\prime}, t} K_{c, t+1}+P_{k_{i}^{\prime}, t} K_{i, t+1}, P_{k_{c}^{\prime}, t}=\Lambda_{k_{c}, t} / \Lambda_{c, t}, P_{k_{i}^{\prime}, t}=\Lambda_{k_{i}, t} / \Lambda_{c, t}$ and $\Lambda_{k_{c}, t}, \Lambda_{k_{i}, t}$ denote the Lagrange multipliers on and (6). Here, $P_{k_{x}^{\prime}, t}$ denotes the consumption good value of a newly installed unit of capital, to be used in production at the beginning of period $t+1$ in sector $x$. Also, $P_{k_{x}, t+1}$ is the value of that same unit of capital at the end of period $t+1$. We refer to $P_{k_{x}^{\prime}, t}$ as the date $t$ price of a share of stock, or a share of equity in sector $x$, where a share corresponds to a claim on a unit of the underlying capital being financed. Under this interpretation, the expression $P_{k_{x}, t+1} / P_{k_{x}^{\prime}, t}$, is the capital gain during that period.

It is straightforward to show that $P_{k_{x}^{\prime}, t}, P_{k_{x}, t}$ and $P_{i, t}$, the consumption-price of an investment good, satisfy the following efficiency condition for investment:

$$
P_{k_{x}^{\prime}, t}=\frac{P_{i, t}}{m p i_{x, t}},
$$


where

$$
m p i_{x, t}=F_{1, t}^{x}+\beta E_{t} \frac{\Lambda_{c, t+1}}{\Lambda_{c, t}} \frac{P_{k_{x}^{\prime}, t+1}}{P_{k_{x}^{\prime}, t}} F_{2, t+1}^{x}
$$

$P_{i}=\Lambda_{i, t} / \Lambda_{c, t}, m p i_{x, t}$ the marginal product of investment in producing installed capital in sector $x$, and $\Lambda_{i, t}$ denotes the Lagrange multiplier on (4). In (11) $F_{1, t}^{x}$ and $F_{2, t}^{x}$ are the first partial derivatives of the function $F$ in (7) evaluated at date $t$ for sector $x=c, i$. Our observations in the introduction about the response of the marginal cost of installed capital to shocks to the demand and supply of investment goods are based on (10). We can see here that a demand shock, which drives $P_{i, t}$ and $I_{x, t}$ both up leads to mutually reinforcing movements of the numerator and denominator in (10), while a supply shock leads to offsetting movements.

The dynamic nature of (11) contrasts with the traditional $q$-theory case where the analogous expression for $m p i_{x, t}$ is not forward looking. See, for example, Cochrane (1991) and Hayashi (1982). Marginal $q$ in sector $x$ is

$$
q_{x, t}=\frac{P_{k_{x, t}^{\prime}}}{P_{i, t}}
$$

Under the rate specification of adjustment costs used in the literature, $m p i_{x, t}$ is just a function of date $t$ investment. Using the efficiency condition (10), it follows that $q_{x, t}$ is a sufficient statistic for investment in sector $x$.

A different relationship between $q$ and investment holds in our model. Log-linearizing (10) about steady state and imposing (11) it is straightforward to derive

$$
\hat{\imath}_{x, t}=\hat{\imath}_{x, t-1}+\frac{1}{\psi} E_{t}\left(\sum_{j=0}^{\infty} \tilde{\beta}^{j} \hat{q}_{x, t+j}\right)
$$

where $\hat{z}_{t}$ is the percent deviation from steady state of variable $z$ and $\tilde{\beta}=\beta \exp (-(\gamma+\mu) /(1-$ $\left.\alpha_{i}\right)$ ). In addition, $i_{x, t}$ denotes $I_{x, t}$ after applying the balanced growth transformation. This expression shows that current investment depends on lagged investment and the expected present discounted value of future marginal q's. Equation (12) is clearly different from the standard $q$ relation. 
In our quantitative analysis, we study the dynamics of an aggregate stock market index, $S_{t}$. Ignoring the debt-equity ratio, the time $t$ value of this index is measured as the total value in current consumption units of end-of-period installed capital. That is,

$$
S_{t}=P_{k_{c}^{\prime}, t} K_{c, t+1}+P_{k_{i}^{\prime}, t} K_{i, t+1}
$$

\section{Assigning Values to the Parameters}

In this section, we discuss the values we assign to our model's parameters. A key aspect of our method is that we do not use most business cycle statistics or any second moment properties of asset returns to estimate the model. These are reserved for testing purposes. There are 13 model parameters:

$$
\beta, \alpha_{c}, \alpha_{i}, \delta, d, \gamma, \mu, b, \psi, \sigma_{\varepsilon}, \sigma_{\nu}, \rho, \omega
$$

The first set of seven parameters control the steady state properties of the model and are chosen by exactly matching the same number of first moments of the data. The remaining six parameters control the business cycle and asset pricing properties of the model. We choose these parameters to optimize the model's ability to account for eight second moments of the data.

\subsection{Parameters Controlling Steady State}

We set

$$
\begin{gathered}
\beta=0.99999, \alpha_{c}=0.45, \alpha_{i}=0.26, \delta=0.021 \\
d=1, \gamma=0.000185, \mu=0.00832
\end{gathered}
$$

The indicated value of $\beta$ was selected to maximize the model's ability to account for the observed low risk free rate. The capital share values are from Hornstein and Prashnick (1997) and differ from BCF who assume equal shares of 0.36. Christiano and Eichenbaum (1992) is our source for $\delta$. We chose a conservative value for $d$. It matches the lower bound 
of the range of empirical estimates of the debt to equity ratio reported in Benninga and Protopapadakis (1990). ${ }^{4}$ It lies below the debt to equity ratios considered in Abel and Blanchard (1986, p.258), who consider $d=2,3$. Nothing essential in our analysis depends on the assumed value of $d$. Finally, there is a linear mapping from steady state consumption and real investment price growth to the growth parameters $\gamma$ and $\mu$. Therefore we choose the growth parameters to match average quarterly consumption growth of 0.0053 and average quarterly price growth of -0.00614 over our sample period 1955-1999.

\subsection{Parameters Controlling Business Cycles and Asset Pricing}

The remaining parameters are $\phi=\left\{b, \psi, \sigma_{\varepsilon}, \sigma_{\nu}, \rho, \omega\right\} .{ }^{5}$ The eight moments of the data used to identify these parameters are:

$$
\begin{array}{cccc}
\rho\left(Y, P_{i}\right)=-0.41 & \rho(Y, S)=0.34 & \operatorname{Er}^{e p}=7.45 & \operatorname{Er}^{f}=1.19 \\
\sigma\left(P_{i}\right) / \sigma(Y)=0.92 & \sigma(S) / \sigma(Y)=5.26 & \sigma(Y)=1.59 & \sigma(C) / \sigma(Y)=0.56
\end{array}
$$

Here, $\rho(x, y)$ and $\sigma(x)$ denotes the correlation between the logged, HP filtered variable $x$ and the similarly filtered variable, $y$ and the standard deviation of the filtered variable $x$. Also, $Y$ denotes aggregate GDP, measured with the chain weighting formula used by the Bureau of Economic Analysis. The variable $r^{e p}$ is the equity premium, the difference between the return on equity and the risk free rate. Finally, $E$ denotes the unconditional expectation operator. See the appendix for the data sources.

With six parameters to identify we require at least six moments of the data. The two correlations in (13) are the observations that motivate this paper. The mean equity premium and risk free rate are the moments used by $\mathrm{BCF}$ to calibrate their model. The relative volatility statistics involving the two prices are natural choices given our desire to understand

\footnotetext{
${ }^{4}$ They argue (footnote 6, p. 54) that the annual average debt to total asset ratio of all U.S. corporations between 1937 and 1984 ranged between $53 \%$ and $75 \%$. Our assumption, $d=1$, translates into a debt to total asset value of $50 \%$.

${ }^{5}$ In the model of GHK the investment price is a direct measure of the investment technology. This is not the case in our model because of the factor immobilities and the different sectoral factor shares. Therefore we cannot use the investment price to estimate the investment technology process directly, i.e estimate $\sigma_{\nu}$, as do Greenwood, et al (2000).
} 
the business cycle dynamics of these variables. A model which accounted for the correlations but not the degree of price volatility would not be credible. We find that without the two remaining statistics, the variance of output and the relative volatility of consumption, then the fit of the model is poor. This is because the model can get closer to the other statistics with higher output volatility and higher consumption volatility.

The metric we used in our optimization procedure is $\mathcal{L}(\phi)$, where

$$
\mathcal{L}(\phi)=\left[\hat{\nu}_{T}-f(\phi)\right] \hat{V}_{T}^{-1}\left[\hat{\nu}_{T}-f(\phi)\right]^{\prime}
$$

Here, $\hat{\nu}_{T}$ is the $8 \times 1$ vector composed of the sample target moments. The $8 \times 8$ matrix $\hat{V}_{T}$ is the diagonal matrix with the inverse of the variances of the estimates in $\hat{\nu}_{T}$. Finally, $f(\phi)$ is an $8 \times 1$ vector of the model's implied values for the target moments. ${ }^{6}$ In the optimization procedure we imposed that parameters must be such that $C_{t} \leq b C_{t-1}$ and $\Lambda_{c, t} \leq 0$ are never observed in the Monte Carlo simulations used to evaluate $f$. Let

$$
J=\mathcal{L}\left(\hat{\phi}_{T}\right)
$$

where $\hat{\phi}_{T}$ minimizes $\mathcal{L}(\phi)$. Under the null hypothesis that the model is true, and ignoring sampling uncertainty in the other parameters, $J$ has a Chi-square distribution with 2 degrees of freedom.

We obtained the following results:

$$
\begin{array}{cc}
\hat{b}=0.76 & \hat{\psi}=6.92 \\
\hat{\sigma}_{\varepsilon}=0.0075 & \hat{\sigma}_{\nu}=0.0094 \\
\hat{\rho}=0.94 & \hat{\omega}=0.98 \\
J=6.26
\end{array}
$$

\footnotetext{
${ }^{6}$ The annual return for a given year is computed as the sum of the rate of return over each quarter in that year. The mapping, $f$, was executed by computing the average of the mean risk free rate and mean equity premium across 500 artificial data sets, each of length 200 quarters.
} 
The value of $J$ indicates the overidentifying restrictions are not rejected at the $3 \%$ level of significance. Presumably with parameter uncertainty the value of $J$ would fall. We conclude that the model plausibly accounts for all of the business cycle variation in output.

Interestingly, some of the parameter estimates are close to values often used in the business cycle literature. In particular, the estimate for the habit parameter is close to the one in $\mathrm{BCF}$ and the persistence of the neutral shock is close to the often assumed value in real business cycle studies. Another notable feature of our estimates is the high estimated value of $\omega$. That this is so close to unity is suggestive of a common source for the technology shocks.

The empirical literature on Tobin's $q$ does not provide direct evidence on $\psi$ because this literature is based on the rate specification for adjustment costs. ${ }^{7}$ To quantify our estimate of $\psi$ we follow the approach of Christiano, et. al. (2003). According to (12) $1 / \psi$ is the elasticity of investment in sector $x$ with respect to a one percent increase in marginal $q$ for that sector. Our point estimate implies that this elasticity is 0.14. Christiano, et. al. (2003) estimate this elasticity to be 0.28 by optimizing their model's ability to account for the consequences of a monetary shock. A more persistent rise in $q^{x}$ induces a larger change in investment. For example, a permanent one percent change in $q^{x}$ induces a $1 /[\psi(1-\tilde{\beta})]=12.6$ percent change change in $x$-sector investment. This value is about $1 / 3$ the one reported by Christiano, et. al. (2003).

\section{Quantitative Findings}

In this section we evaluate the interpretation summarized in the introduction regarding the divergent cyclical behavior of stock market and investment good prices. We document how the various features of our calibrated model contribute to accounting for this phenomenon. We then build confidence in our interpretation by evaluating the model's asset pricing and business cycle implications. Overall, the model does well on this test. The modifications

\footnotetext{
${ }^{7}$ See Christiano and Fisher (1997) for a discussion of the empirical Tobin's $q$ literature as it relates to a business cycle model like the one here, but with the rate specification of adjustment costs.
} 
we introduce into BCF to articulate our hypothesis do not change that model's superior empirical performance. Moreover, the modifications lead to a substantial improvement, by enabling the model to account for sectoral co-movement in both output and factor inputs.

\subsection{Stock Market and Investment Good Prices}

Table 1 presents the statistics summarizing the business cycle dynamics of stock market and investment good prices. The basic layout is common to all the tables considered. The first column presents various statistics from the data ('Data'). The column marked 'Calibrated' reports results using the parameter values from the calibration described in the previous section. The columns to the right of that report results based on perturbing the value, as indicated in the column header, of one model parameter. In each case, the other parameter values are kept at their calibrated values.

Panel A of Table 1 shows the model's implications for stock market and investment good prices. This shows that the calibrated model is close to the data in terms of the sign switch in the correlation with output of stock market and investment good prices and in terms of business cycle volatility. We begin our discussion of this finding by documenting the contributions of the two-shock and adjustment cost assumptions to explaining the signswitch phenomenon. When adjustment costs are eliminated (see the column marked ' $\psi=0$ '), or there is only a neutral shock (' $\sigma_{\nu}=0$ '), then the model loses its ability to account for the sign switch. This is to be expected. Adjustment costs are the wedge between stock market

and investment good prices (recall (10)). Eliminate the wedge, and the difference in the behavior between the two prices disappears too. Also, with only neutral shocks there are only sources of procyclicality in the two prices.

Further insight into our calibrated model's account for the sign switch may be obtained from Figure 1. That figure displays the response of the capital prices and the stock index to neutral (right column) and investment-specific shocks (right column). In Figure 1 the correlation between the shocks is ignored. Consider the response to the neutral shock. There is a sharp rise in both the investment good price, $P_{i}$, as well as the prices of installed capital, 
$P_{k_{c}^{\prime}}$ and $P_{k_{c}^{\prime}}$, and the stock index, $S$. Consistent with the intuition in the introduction, the jump in the stock index price exceeds that in the price of investment goods. Now consider the response to an investment-specific technology shock. As anticipated in the introduction, Figure 1 shows that $S$ falls relatively little, by comparison with $P_{i}$.

The intuition underlying the sign-switch property in the model suggests a one-shock hypothesis, involving only the investment-specific shock, might be capable of accounting for the sign switch, if the installation costs rise fast enough with investment growth. Under the adjustment cost assumptions used here, the one-shock hypothesis is not capable of accounting for the sign switch. That is, we could not find a value of $\psi$ such that the model could account for the sign switch under the one-shock hypothesis. Simply setting the variance of the neutral shock to zero without raising the degree of adjustment costs of course does not work, since both prices are countercyclical with respect to the investment-specific shock in this model $\left(\sigma_{\varepsilon}=0{ }^{\prime}\right){ }^{8}$

Panel A of Table 1 also shows that the model accounts well for the cyclical volatility of investment and equity prices. In the data, equity prices are 5 and $1 / 4$ times as volatile as output and investment goods prices are a little less volatile that output. That the relative volatility of the capital prices is about right in the calibrated model, seems to depend a lot on the two shocks being highly correlated (' $\omega=0$ '). Note that the Shiller (1981) "excess volatility" of equity puzzle does not stand here. However, this seems in part to be due to the model's (counterfactual, as we will see) high volatility in interest rates.

We conclude by noting that our model's success with respect to the sign-switch does not depend on the growth specification for adjustment costs. For example, Christiano and Fisher (1997) describe a model similar to that here except that it has the rate specification of adjustment costs. The calibrated version of that model also exhibits the sign-switch phenomenon. The reasons are similar to those discussed here. While accounting for the sign-switch, that model overstates the volatility of both prices.

\footnotetext{
${ }^{8}$ Christiano and Fisher (1997) show that with the rate specification of adjustment costs that a one-shock model can match the sign-switch. They discuss several reasons why this hypothesis is dominated by the two-shock hypothesis.
} 


\subsection{Asset Returns}

The asset pricing performance of our calibrated model, shown in Panel B of Table 1, is comparable to that of $\mathrm{BCF}$. The model does well accounting for the mean equity premium and risk free rate as well as the Sharpe ratio, $E r^{e-p} / \sigma_{r e}$ and the variance of equity returns. As with BCF, and other models with the habit specification used here, the model does poorly with respect to the volatility of the risk free rate.

As can be anticipated from BCF, the equity premium disappears when the innovation of the aggregate technology shock is set to zero (' $\sigma_{\varepsilon}=0$ '), and is virtually unaffected by setting the innovation in the investment-specific shock to zero $\left({ }^{6} \sigma_{\nu}=0\right.$ '). These latter findings reflect that the equity premium depends on the one-step-ahead uncertainty in aggregate consumption.

The risk free rate hardly responds to the investment specific shock (' $\sigma_{\varepsilon}=0$ '), but responds a lot to the neutral shock (' $\sigma_{\nu}=0$ '). This reflects (i) that the investment-specific shock has no current period impact on consumption, while the neutral shock does, (ii) the primary avenue by which a shock affects the risk free rate in the model is via the current period marginal utility of consumption and (iii) the marginal utility of consumption is sensitive to current consumption under habit persistence.

The strong response in the risk free rate to the neutral shock is the reason our model overstates by several factors the volatility of the risk free rate (' $\sigma_{\nu}=0$ '). The poor performance of the model on this dimension is comparable to that of BCF. ${ }^{9}$ The response of the rate of return on equity to the neutral shock is also strong, but this is about right (' $\sigma_{\nu}=0$ '). Interestingly, unlike the stock market and investment good prices, the behavior of asset returns is virtually unrelated to the high correlation of the two shocks (' $\omega=0$ ').

\footnotetext{
${ }^{9}$ Our findings on the volatility of asset returns are consistent with those in of Heaton (1995). One of Heaton's findings is that the ability to account for first moments of asset returns comes at a cost of poor performance on second moments. Although this appears to be a feature of our model too, the results of Campbell and Cochrane (1995) suggest that this need not be a feature of models with habit persistence generally.
} 


\subsection{The Business Cycle}

We now turn to the business cycle implications of our model. We first discuss the implications for key aggregate business cycle statistics mentioned in the introduction: measures of volatility and comovement, persistence, the excess-sensitivity of consumption puzzle, and the leading indicator phenomenon. We then discuss how our model accounts for sectoral co-movement in factor inputs.

\subsubsection{Aggregate Business Cycle Statistics}

Table 2 presents the implications of our model for certain aggregate business cycle statistics. The results in the 'Data' column are based on data from the NIPA and data from our model are calculated in a consistent way. For example, aggregate output in the model is calculated using the BEA's chain-weighting method. Figure 2 displays the response of output, investment, consumption and hours to the two shocks, again ignoring their correlation.

\section{Volatility and Comovement}

Consistent with the way we calibrated our model, the model does well accounting for output and consumption volatility (see Panel A, Table 2). The results suggest that both shocks must be present and these shocks must be highly correlated for this to be the case. The other statistics were not used in the calibration, and consistent with standard models as well as the model in BCF, the model does well here as well. In particular, consumption, investment and hours all comove positively with output and investment is more volatile than output.

The main deviations from the unconditional moments in the data are that hours and investment are not volatile enough. In at least one respect this is not a problem for the model. Specifically, the estimates of the fraction of hours worked accounted for by the technology shocks is similar to that estimated by Fisher (2003) using a reduced form model. Still, to the extent that we have sought to account for the entire business cycle with the shocks in the model, this might be viewed as a drawback of the model. The volatility 
failures are common drawbacks for a business cycle model that might be overcome by the addition of other model features, such as endogenous capacity utilization.

The source of the shocks has little impact on the volatility of hours, (' $\psi=0$ ', ' $\sigma_{\nu}=0$ ', and ' $\omega=0$ '). Interestingly, removing adjustment costs (' $\psi=0$ ') worsens the model's prediction for the relative volatility of hours. This contrasts sharply with a model based on the rate adjustment cost specification, such as Christiano and Fisher (1997), where the adjustment costs are a force for smoothing hours relative to output. In section 2.2 , we emphasized this drawback of the rate specification as one of the two main reasons for choosing to work with our growth specification. Under both adjustment cost specifications, the absolute volatility of hours rises when adjustment costs are removed.

Interestingly, the adjustment costs are not that important for the smoothness of investment relative to output (' $\psi=0$ '). The relatively weak response of investment to a neutral shock (' $\sigma_{\nu}=0$ ') and the high correlation between the two shocks (' $\omega=0$ ') are crucial here. Of course the adjustment costs do affect the absoluate volatility of investment.

\section{Persistence}

Macroeconomists have for a long time sought to identify factors which propagate the effects of economic shocks over time. It is well known that standard real business cycle models do poorly on this dimension. Due in part to its incorporating the features in BCF, our model does quite well on this dimension (see Panel B, Table 2). Figure 2 shows investment, output and hours displays hump shaped responses to both shocks in the calibrated model. Consumption responds slowly and persistently to the investment-specific shock. In response to a neutral shock, consumption displays little persistence beyond that already in the shock.

It is interesting to note how curvature in adjustment costs enhance the model's internal propagation mechanism. Thus, when curvature is eliminated (' $\psi=0$ '), then output persistence drops to -0.45 . This is just a feature of the strong propagation effect the growth adjustment cost specification imparts on a model. In section 2.2, we gave this as the second main reason for adopting the growth adjustment cost specification over the rate specification. 
The model's implications for consumption persistence may seem counterfactual. Because of the limitations on the intersectoral mobility of resources, consumption responds immediately to the neutral shock and slowly to the investment-specific shock. The response to the first shock generates negative autocorrelation in consumption growth (' $\sigma_{\nu}=0$, Panel B'), while the response to the second generates positive autocorrelation (' $\sigma_{\varepsilon}=0$, Panel B'). The net outcome with both shocks is about zero.

The model's zero autocorrelation in consumption growth misses the corresponding empirical estimate, which is positive and statistically significant. We are not very concerned about this failure. First, temporal aggregation, as considered by Christiano, Eichenbaum and Marshall (1991), could account for the positive correlation in the data. Moreover, it is common in asset pricing studies to assume consumption is a random walk, e.g. Campbell and Cochrane (1999).

\section{Excess Sensitivity of Consumption to Income}

We now turn to the statistical evidence which Campbell and Mankiw (1989, 1991) (CM) argue is a puzzle from the perspective of equilibrium business cycle models. The implications of our model for this evidence are displayed in Panel C, Table 2.

$\mathrm{CM}$ estimate a linear expression relating the predictable component of consumption growth to the predictable component of income growth and to the interest rate. Applying instrumental variables techniques, they find that the estimated coefficient on income, $\lambda$, is about $1 / 2$, while the coefficient on the interest rate, $\theta$, is close to zero. Appealing to standard consumption models, CM argue that household maximization implies the coefficient on income should be zero and the coefficient on the interest rate should be large. In these models, the level of consumption is determined by household wealth and its growth rate is determined solely by the rate of interest. The coefficient on the interest rate is the reciprocal of the coefficient of relative risk aversion. This coefficient should be substantially above zero on the assumption that risk aversion is small.

CM interpret the evidence as indicating that the representative agent, optimizing framework should be abandoned as a way of thinking about fluctuations. Just as in BCF, our 
results suggest another interpretation. The modifications introduced into the standard model to help it account for asset prices also have the effect of raising the implied estimated value of $\lambda$ and reducing the implied estimated value of $\theta$. Given that our model shares these modifications, it also does well along this dimension (see BCF for a detailed discussion of why this is so.) Indeed, our model is superior to the one in BCF since its implied value for $\lambda$ is smaller and closer to the CM estimate. Panel C, Table 2 shows that the investment-specific shock is largely responsible for this (' $\sigma_{\varepsilon}=0$ '). Thus, an alternative interpretation of CM's findings is that they provide corroborating evidence in favor of our model.

\section{Inverted Leading Indicator Phenomenon}

Nominal interest rates appear to covary positively with past (detrended) levels of output and negatively with future levels. ${ }^{10}$ This can be seen in Table 2, Panel D, which displays the dynamic correlations between the Federal Funds rate and detrended output. They represent a key factor underlying the belief of some researchers that monetary policy shocks play an important role in the dynamics of the business cycle. One reason for this belief is that the monetary policy shock interpretation seems straightforward. Another reason, which appears to receive support in the results of King and Watson (1996), reflects the view that standard models are incapable of accounting for the negative association between interest rates and future output. BCF find that the two-sector model which incorporates changes designed to account for asset returns is not. It is consistent with the inverted leading indicator phenomenon. This suggests that the dynamic economic behavior attributed to monetary disturbances may, at least in part, also reflect the effects of real disturbances propagated via mechanisms like those captured by our model.

Our findings in Table 3, Panel $\mathrm{C}$ show that the modifications to the BCF model introduced to account for the capital price dynamics do not diminish the ability of the model to account for the leading indicator phenomenon. ${ }^{11}$ The reasons for the success of the model

\footnotetext{
${ }^{10}$ The result for real interest rates, e.g. Fiorito and Kollintzas (1994), is not robust to alternative ways of measuring real interest rates.

${ }^{11}$ Without loss of generality Panel C, Table 2 displays real interest rate-output correlations. This is without loss of generality, because it is straightforward to introduce money into the model such that it is neutral
} 
are similar to those in BCF. Mechanically, the positive correlation between the interest rate and current and future output reflects that a positive shock to the neutral technology drives up the rate of interest and also drives up current and future output. The responses to an investment-specific shock work in the other direction (' $\sigma_{\varepsilon}=0$ ') and the adjustment costs seem to help (' $\psi=0$ ').

\subsubsection{Sectoral Co-movement of Factor Inputs}

It has been extensively documented that employment and investment move up and down together across economic sectors, e.g. Christiano and Fitzgerald (1998). As BCF discuss, standard models are inconsistent with these observations. In particular, while they predict consumption and investment output are procyclical, they also predict factor inputs are countercyclical in the consumption sector.

Table 3 and Figure 3 document that our model produces strong comovement over the cycle in sectoral employment and investment. As in $\mathrm{BCF}$, habit persistence and factor market inflexibilities are necessary for our model to produce comovement in employment. However, the BCF model only has employment comovement. In our model both employment and investment respond positively to each shock. Table 3 shows that the adjustment costs are important for this finding (' $\psi=0$ ').

One can understand why our model has sectoral investment comovement while model's such as BCF's do not, by considering (12) and Figure 1. Figure 1 shows that the responses of the installed capital prices are almost identical. Therefore, by (12), it must be that investment in the sectors move together. In BCF, $P_{i .}=P_{k_{x}^{\prime}}$ so that $q_{x}=1$ and there is no variation in marginal $q$. Therefore this source of comovement is not in that model. Our model with $\psi=0$ shares this property and so also has trouble with investment comovment.

We conclude by noting that our model's success with respect to comovement does not depend on the growth specification for adjustment costs. For example, the calibrated model of Christiano and Fisher (1997) also exhibits sectoral input comovement. The reason is

for quantities, yet its implications for the nominal interest rate correlations are virtually identical to the corresponding real interest rate correlations. See Christiano and Fisher (1997) for how this can be done. 
similar to the reason given here, because sectoral installed capital prices comove strongly there as well.

\section{Other Explanations of Stock Market and Investment Good Prices}

There are two leading alternative theories of why stock prices and investment prices behave so differently over the business cycle. Both theories involve different interpretations of the negative correlation between investment prices and output.

Murphy, Shleifer and Vishny (1989) infer that the business cycle is driven by a shock to the demand for investment goods, and that there are increasing returns in the production of investment goods. The empirical evidence seems to go against this interpretation, however. For example, although Harrison (1998) provides some empirical support for the notion that there are increasing returns associated with capital and labor in the production of investment goods, the degree of increasing returns she finds is not sufficient to generate increasing returns in the factor of production, labor, that is variable in the short run. This is consistent with the findings of Goolsby (1998) and Shea (1993), who find that supply curves slope up. Goolsby's analysis focuses specifically on the supply of capital goods.

Another possible interpretation of countercyclical investment good prices is that markups in the investment good sector are countercyclical, or more generally, that they are more so than in the consumption good sector. A model with the potential to formally articulate this possibility has been described by Jaimovich (2003). In his model of imperfect competition a positive neutral technology shock encourages entry by firms, which in turn reduces markups. Since investment responds more than consumption to neutral technology shocks, such a model should predict that the relative price of investment goods falls in a business cycle boom driven by neutral shocks. It would be interesting to see evaluate whether the conclusion regarding the nature of technology shocks arrived at here would stand up with such a model calibrated to the same moment as here. More generally, this hypothesis seems more promising than the increasing returns theory so it is of interest to investigate it further. 


\section{Concluding Remarks}

We used the business cycle properties of stock market prices and investment good prices to draw inferences about the source of business cycle shocks and the nature of capital installation costs. We achieved identification using an explicitly formulated model.

As in Greenwood, Hercowitz and Krusell $(1997,2000)$, we infer that the countercyclical nature of investment good prices reflects the effects of supply shocks in the investment sector. Our analysis suggests that a second shock also plays a role in the business cycle. In addition, we interpret the fact that investment good and stock market prices behave differently as reflecting the presence of costs for installing new capital.

To test these inferences, we go beyond simply constructing a model that can account quantitatively for the observations that interest us. We also investigate the model's implications for other business cycle and asset pricing phenomena. We find that the model does well on these dimensions. Moreover, in some respects, the model actually represents a step forward. In particular, unlike standard models and BCF, our model is consistent with sectoral comovement in factor inputs.

We sought to draw out the shortcomings of our analysis. On the asset pricing side, our model inherits the difficulties that $\mathrm{BCF}$ has in accounting for the volatility of the risk free rate. On the business cycle side, our model has difficulties with the labor market and the volatility of investment. Resolving these shortcomings constitutes a task for future research. 


\section{Appendix}

Below we list the data series used in our analysis. The Haver database mnemonic for the series is indicated where appropriate.

1. Aggregate price data. The real investment price is measured as the price index for investment divided by the price index for consumption. We use the adjustments described in Fisher (2003) to correct for quality bias in the NIPA equipment price deflator. The stock index is the New York Stock Exchange composite (SPNY) divided by the consumption deflator. chain-weighted dollars.

2. Asset return data. The real risk free rate and the real return on equity are from Ibbotson Associates. The nominal interest rate is the Federal Funds rate (FFED).

3. Aggregate quantity data. When series are added together they are chain weighted. Output (GDPH), Consumption (Consumption of nondurables and services, $\mathrm{CNH}+$ $\mathrm{CSH}$ ), Investment (Private nonresidential investment, GFNSH+GFNEH, where the adjustment to the equipment deflator discussed in Fisher (2003) are used in the chainweighting). Chain-weighting requires the nominal version of the series listed above (mnemonics for these series are the same as for the real series listed above with the last letter removed.) Hours worked are private nonfarm (LXNFH).

4. Sectoral data. Hours and investment in the consumption sector are proxied with the service sector variables (LIPSRVA, ZPPSQ) and hours and investment in the investment sector are proxied with the durables manufacturing variables (LIDURGA, ZPPMDQ). 


\section{References}

Abel, Andrew, and Olivier Blanchard, 1986, 'The Present Value of Profits and Cyclical Movements in Investment,' Econometrica, vol. 54, no. 2 March, pp. 249-73.

Benninga, Simon and Aris Protopapadakis, 1990, 'Leverage, time preference and the equity premium puzzle,' Journal of Monetary Economics, vol. 25, pp. 49-58.

Boldrin, Michele, Lawrence J. Christiano, and Jonas D.M. Fisher, 2001, 'Habit Persistence, Asset Returns, and the Business Cycle." American Economic Review.

Campbell, John Y., and John H. Cochrane, 1999, 'By force of habit: A consumption-based explanation of aggregate stock market behavior,' Journal of Political Economy.

Campbell, John, and N. Gregory Mankiw, 1989, 'Consumption, income, and interest rates: reinterpreting the time series evidence,' in Blanchard and Fischer, editors, NBER Macroeconomics Annual 1989.

Campbell, John, and N. Gregory Mankiw, 1991, 'The response of consumption to income: a cross-country investigation,' European Economic Review, vol. 35, pp. 723-767.

Christiano, Lawrence J., 1998, 'Solving Dynamic Equilibrium Models by a Method of Undetermined Coefficients', National Bureau of Economic Research Technical Working Paper, January.

Christiano, Lawrence J., and Martin Eichenbaum, 1992, 'Current real-business-cycle theories and aggregate labor-market fluctuations,' American Economic Review, vol. 82, pp. $430-450$.

Christiano, Lawrence J., Martin Eichenbaum and Charles Evans, 2003, 'Nominal Rigidities and Monetary Policy Shocks".

Christiano, Lawrence J., Martin Eichenbaum and Robert Vigfussen, 2003, 'What Happens After a Technology Shock?. Northwestern manuscript..

Christiano, Lawrence J., Martin Eichenbaum and David Marshall, 1991, 'The Permanent Income Hypothesis Revisited,' Econometrica 59, no. 2, March.

Christiano, Lawrence J. and Jonas D. M. Fisher, 1995, 'Tobin's $q$ and Asset Returns: Implications for Business Cycle Analysis,' NBER working paper 5292.

Christiano, Lawrence J. and Jonas D. M. Fisher, 1998, 'Stock Market and Investment Good Prices: Implications for Macroeconomics." Chicago Fed Working Paper 1998-xx.

Christiano, Lawrence J. and Jonas D. M. Fisher, 1998, 'Technical Appendix to Stock Market and Investment Good Prices: Implications for Macroeconomics', manuscript.

Christiano, Lawrence J. and Terry Fitzgerald, 19, 'The Business Cycle: Its still a Puzzle.' Chicago Fed's Economic Perspectives.

Cochrane, John, 1991, 'Production-Based Asset Pricing and the Link between Stock Returns and Economic Fluctuations,' Journal of Finance, vol. 46, no. 1, March, pp. 209-37.

Constantinides, George, 1990, 'Habit formation: A resolution of the equity premium puzzle,' Journal of Political Economy, vol. 98, pp. 519-542. 
Fiorito, Riccardo and Tryphon Kollintzas, 1994, 'Stylized Facts of Business Cycles in the G7 from a Real Business Cycles Perspective,' European Economic Review, vol. 38, no. 2, pp. 235-69.

Fischer, Stanley, and Robert C. Merton, 1984, 'Macroeconomics and Finance: The Role of the Stock Market,' in Karl Brunner and Allan H. Meltzer, eds., Essays On Macroeconomic Implications of Financial and Labor Markets and Political Processes, CarnegieRochester Conference Series on Public Policy, 21, pp. 57-108.

Fisher, Jonas D.M., 2002, "Technology Shocks Matter." Chicago Fed Working Paper 200214.

Gali, Jordi, 1999, "Technology, Employment, and the Business Cycle: Do Technology Shocks Explain Aggregate Fluctuations?" American Economic Review.

Goolsbee, Austan, 1998, 'Investment Tax Incentives, Prices, and the Supply of Capital Goods,' Quarterly Journal of Economics, vol. 113, issue 1, pp. 121-148, February.

Greenwood, Jeremy, Zvi Hercowitz, and Per Krusell, 1997, 'Long-Run Implications of Investment-Specific Technological Change,' American Economic Review, vol. 87, no. 3, June, pp. 342-362.

Greenwood, Jeremy, Zvi Hercowitz, and Per Krusell, 2000, 'The Role of Investment-Specific Technological Change in the Business Cycle,' European Economic Review.

Harrison, Sharon G., 1998, Evidence on the empirical plausibility of externalities and indeterminacy in a two sector model, unpublished manuscript, Barnard College, Columbia University.

Hayashi, Fumio, 1982, ' Tobin's Marginal q and Average q: A Neoclassical Interpretation,' Econometrica, vol. 50, no. 1, January, pp. 213-24.

Heaton, John, 1995, 'An empirical investigation of asset pricing with temporally dependent preference specifications,' Econometrica 63, 681-717.

Hornstein, Andreas, and J. Praschnik, 1997, 'Intermediate Inputs and Sectoral Comovement in the Business Cycle,' Journal of Monetary Economics, pp. 573-595.

Jaimovich, Nir, 2003, "Countercyclical Markups and the Business Cycle." Northwestern manuscript.

King, Robert and Mark Watson, 1996, 'Money, Prices, Interest Rates and the Business Cycle,' The Review of Economics and Statistics, vol. LXXVIII, no. 1, pp. 35-53.

Masulis, Ronald W, 1988, The debt/equity choice. Cambridge, MA: Ballinger.

Murphy, Kevin M., Andrei Shleifer, and Robert W. Vishny, 1989, 'Building blocks of market clearing business cycle models,' NBER Macroeconomics Annual 1989, edited by Olivier J. Blanchard and Stanley Fischer, MIT Press.

Shea, John, 1993, 'Do Supply Curves Slope Up?', Quarterly Journal of Economics, vol. 108, February, pp. 1-32.

Shiller, Robert, 1981, 'Do stock prices move too much to be justified by subsequent changes in dividends?' American Economic Review, vol. 71, pp. 421-436.

Sundaresan, Suresh M., 1989, 'Intertemporally dependent preferences and the volatility of consumption and wealth,' Review of Financial Studies, vol. 2, pp. 73-89. 
Table 1: Captial Prices and Asset Returns

\begin{tabular}{lllllll} 
Statistic $^{(\mathrm{i})}$ & Data $^{(\mathrm{i})}$ & Calibrated & $\psi=0$ & $\sigma_{\varepsilon}=0$ & $\sigma_{\nu}=0$ & $\omega=0$ \\
\hline
\end{tabular}

Panel A: Stock Market and Investment Good Prices

\begin{tabular}{|c|c|c|c|c|c|c|}
\hline$\rho\left(Y, P_{i}\right)$ & $\begin{array}{l}-0.41 \\
(0.12)\end{array}$ & -0.42 & 0.29 & -0.29 & 0.31 & 0.11 \\
\hline$\rho(Y, S)$ & $\begin{array}{r}0.34 \\
(0.10)\end{array}$ & 0.23 & 0.30 & -0.79 & 0.34 & 0.27 \\
\hline$\sigma\left(P_{i}\right)$ & $\begin{array}{r}0.92 \\
(0.11)\end{array}$ & 0.93 & 0.80 & 10.3 & 5.24 & 6.54 \\
\hline$\sigma(S)$ & $\begin{array}{r}5.26 \\
(0.58)\end{array}$ & 5.47 & 0.78 & 1.62 & 8.49 & 7.64 \\
\hline \multicolumn{7}{|c|}{ Panel B: Asset Returns } \\
\hline$E r^{e p}$ & $\begin{array}{r}7.45 \\
(2.22)\end{array}$ & 7.09 & 9.52 & 0.07 & 7.80 & 7.81 \\
\hline$E r^{f}$ & $\begin{array}{r}1.34 \\
(0.34)\end{array}$ & 2.06 & 2.45 & 2.14 & 2.07 & 2.09 \\
\hline$\sigma\left(r^{e}\right)$ & $\begin{array}{r}31.3 \\
(2.59)\end{array}$ & 25.6 & 29.4 & 3.03 & 28.8 & 28.6 \\
\hline$\sigma\left(r^{f}\right)$ & $\begin{array}{r}2.61 \\
(0.23)\end{array}$ & 18.8 & 23.2 & 0.44 & 19.1 & 19.1 \\
\hline$/ \sigma\left(r^{e p}\right)$ & $\begin{array}{r}0.24 \\
(0.08)\end{array}$ & 0.20 & 0.23 & 0.02 & 0.20 & 0.20 \\
\hline
\end{tabular}

Notes to Table 1: (i) See the text for an explanation of the notation; (ii) See the Appendix for the data sources. 
Table 2: Aggregate Business Cycle Statistics

\begin{tabular}{|c|c|c|c|c|c|c|}
\hline Statistic $^{(i)}$ & Data ${ }^{(i i)}$ & Calibrated & $\psi=0$ & $\sigma_{\varepsilon}=0$ & $\sigma_{\nu}=0$ & $\omega=0$ \\
\hline \multicolumn{7}{|c|}{ Panel A - Volatility and Comovement } \\
\hline$\sigma_{Y}$ & $\begin{array}{r}1.59 \\
(0.16)\end{array}$ & 1.65 & 13.9 & 0.56 & 1.12 & 1.26 \\
\hline$\sigma_{C} / \sigma_{Y}$ & $\begin{array}{r}0.56 \\
(0.04)\end{array}$ & 0.57 & 0.06 & 0.13 & 0.86 & 0.77 \\
\hline$\sigma_{I} / \sigma_{Y}$ & $\begin{array}{r}2.99 \\
(0.19)\end{array}$ & 1.76 & 1.91 & 2.65 & 1.29 & 1.65 \\
\hline$\sigma_{H} / \sigma_{Y}$ & $\begin{array}{r}1.10 \\
(0.05)\end{array}$ & 0.46 & 0.29 & 0.54 & 0.41 & 0.44 \\
\hline$\rho(Y, C)$ & $\begin{array}{r}0.79 \\
(0.05)\end{array}$ & 0.96 & 0.40 & 0.21 & 0.98 & 0.88 \\
\hline$\rho(Y, I)$ & $\begin{array}{r}0.78 \\
(0.04)\end{array}$ & 0.99 & 0.99 & 0.99 & 0.97 & 0.93 \\
\hline$\rho(Y, H)$ & $\begin{array}{r}0.87 \\
(0.03)\end{array}$ & 0.68 & 0.19 & 0.75 & 0.66 & 0.68 \\
\hline \multicolumn{7}{|c|}{ Panel B - Persistence } \\
\hline$\rho(\Delta Y)$ & $\begin{array}{r}0.31 \\
(0.07)\end{array}$ & 0.13 & -0.47 & 0.24 & 0.10 & 0.13 \\
\hline$\rho(\Delta C)$ & $\begin{array}{r}0.42 \\
(0.07)\end{array}$ & -0.02 & -0.12 & 0.97 & -0.02 & -0.01 \\
\hline
\end{tabular}

Panel C - Excess Sensitivity of Consumption to Income $\mathrm{e}^{(\mathrm{iii})}$

\begin{tabular}{|c|c|c|c|c|c|c|}
\hline \multicolumn{7}{|c|}{$\Delta C_{t}=\mu+\lambda \Delta Y_{t}+\theta r_{t-1}^{f}+\varepsilon_{t}$} \\
\hline$\lambda$ & $\begin{array}{r}0.47 \\
(0.15)\end{array}$ & 0.46 & 0.02 & -0.002 & 0.80 & 0.78 \\
\hline$\theta$ & $\begin{array}{c}0.089 \\
(0.11)\end{array}$ & 0.002 & 0.003 & 0.91 & 0.01 & 0.003 \\
\hline \multicolumn{7}{|c|}{ Panel D - Inverted Leading Indicator Phenomenon } \\
\hline$\rho\left(r_{t-4}^{f}, Y_{t}\right)$ & $\begin{array}{c}-0.54 \\
(0.14)\end{array}$ & -0.19 & -0.05 & 0.22 & -0.20 & -0.18 \\
\hline$\rho\left(r_{t}^{f}, Y_{t}\right)$ & $\begin{array}{r}0.35 \\
(0.08)\end{array}$ & -0.24 & -0.26 & 0.25 & -0.28 & -0.25 \\
\hline$\rho\left(r_{t+4}^{f}, Y_{t}\right)$ & $\begin{array}{r}0.45 \\
(0.11)\end{array}$ & 0.21 & 0.07 & -0.21 & 0.21 & 0.19 \\
\hline
\end{tabular}

Notes to Table 2: (i) See the text for an explanation of the notation; (ii) See the Appendix for the data sources. (iii) See BCF for details on how we did these calculations. 
Table 3: Sectoral Comovement of Factor Inputs

\begin{tabular}{|c|c|c|c|c|c|c|}
\hline Statistic $^{\mathrm{b}}$ & $\operatorname{Data}^{\mathrm{c}}$ & Calibrated & $\psi=0$ & $\sigma_{\varepsilon}=0$ & $\sigma_{\nu}=0$ & $\omega=0$ \\
\hline$\rho\left(Y, H_{c}\right)$ & $\begin{array}{c}0.81 \\
(0.04)\end{array}$ & 0.76 & 0.20 & 0.41 & 0.77 & 0.71 \\
\hline$\rho\left(Y, H_{i}\right)$ & $\begin{array}{c}0.90 \\
(0.03)\end{array}$ & 0.68 & 0.19 & 0.75 & 0.65 & 0.67 \\
\hline$\rho\left(Y, I_{c}\right)$ & $\begin{array}{c}0.73 \\
(0.08)\end{array}$ & 0.99 & -0.27 & 0.98 & 0.99 & 0.93 \\
\hline$\rho\left(Y, I_{i}\right)$ & $\begin{array}{c}0.49 \\
(0.08)\end{array}$ & 0.95 & 0.36 & 0.98 & 0.92 & 0.89 \\
\hline
\end{tabular}

Notes to Table 3: (i) See the text for an explanation of the notation; (ii) See the Appendix for the data sources. 
Figure 1: Capital Prices

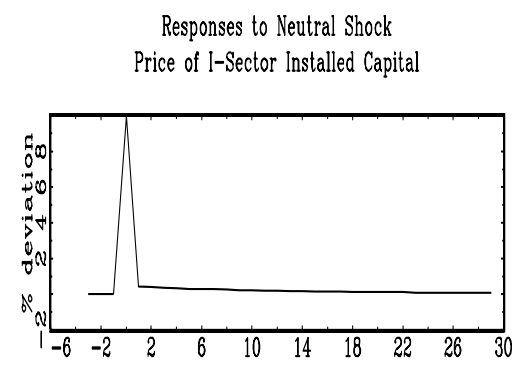

Responses to Investment-Specific Shock

Price of I-Sector Installed Capital

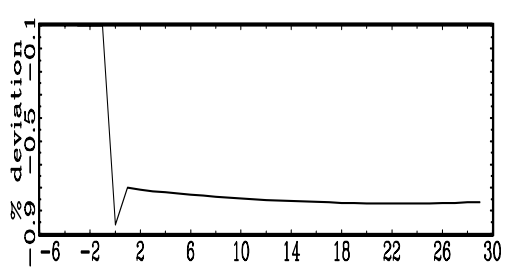

Price of C-sector Installed Capital

Price of C-sector Installed Capital
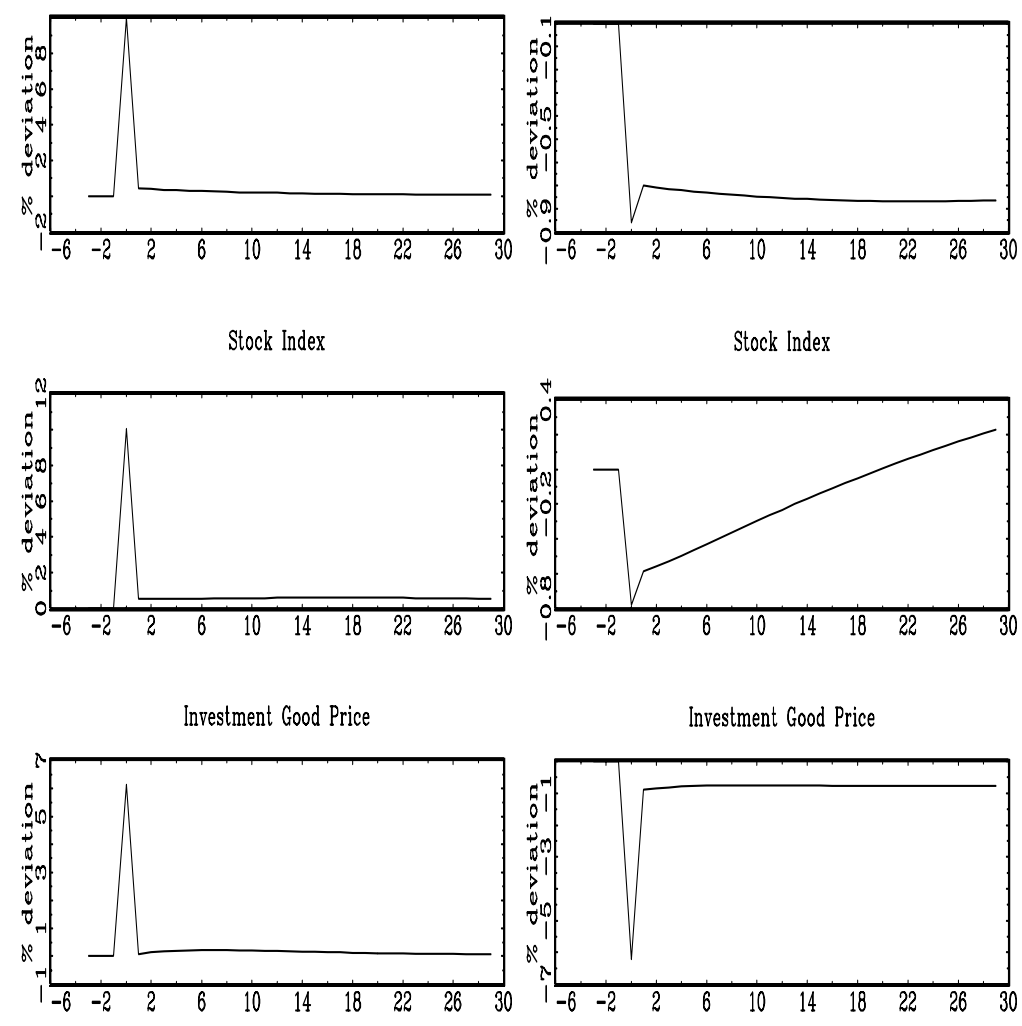
Figure 2: Aggregate Quantities

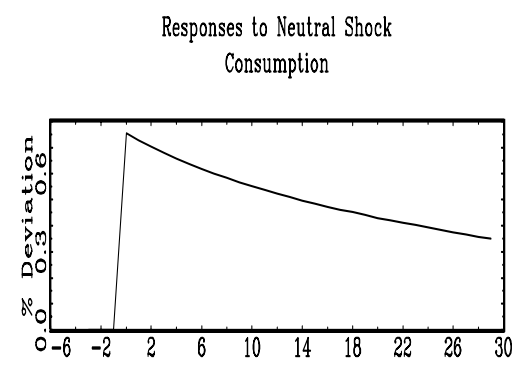

Responses to Investment-Specific Shock Consumption

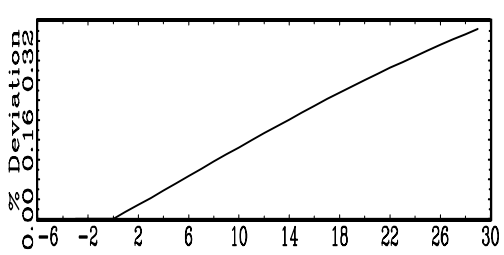

Investment

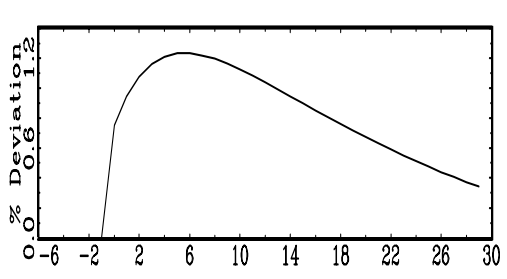

Hours Norked

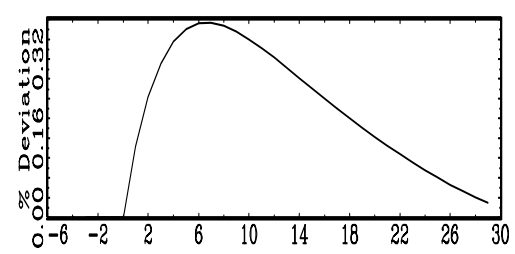

Output

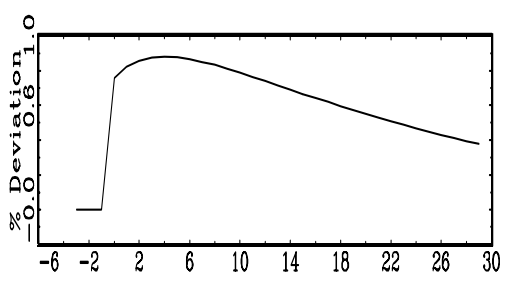

Investment

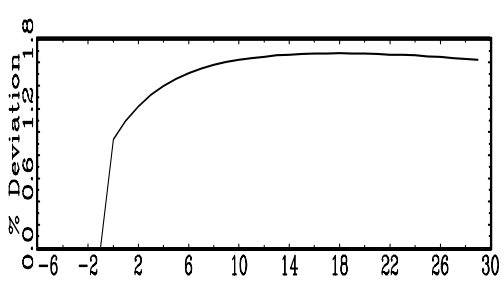

Hours Worked

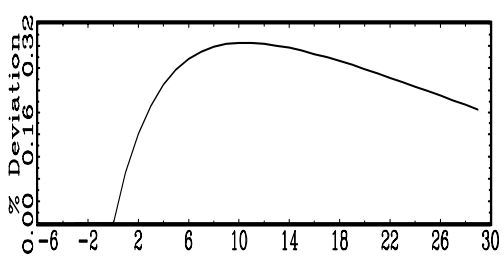

Output

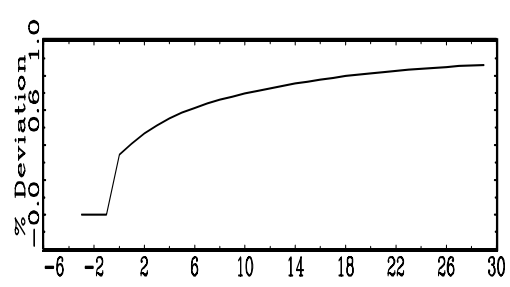


Figure 3: Sectoral Comovement of Factor Inputs

Responses to Neutral Shock Hours in the Consumption Sector

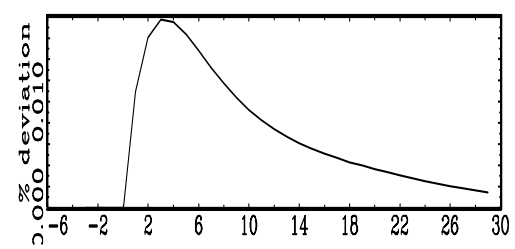

Hours in the Investment Sector

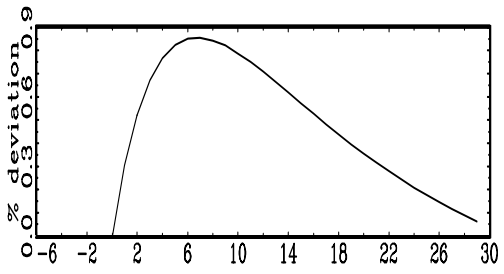

Investment in the Consumption Sector

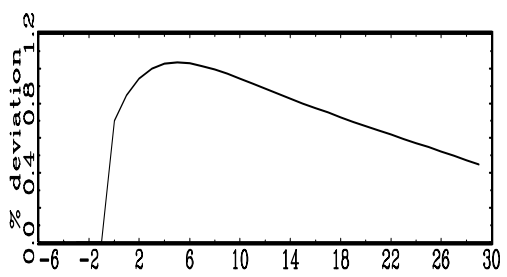

Investment in the Investment Sector

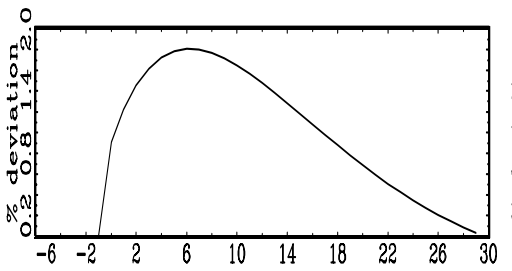

Responses to Investment-Specific Shock

Hours in the Consumption Sector

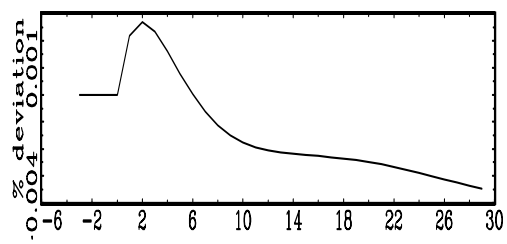

Hours in the Investment Sector

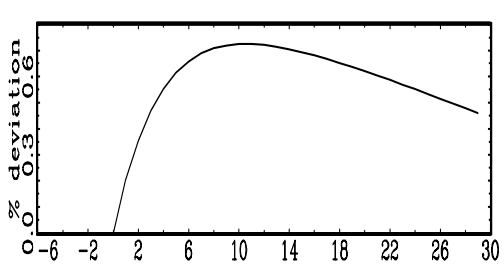

Investment in the Consumption Sector

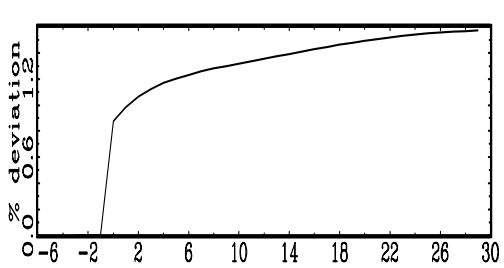

Investment in the Investment Sector

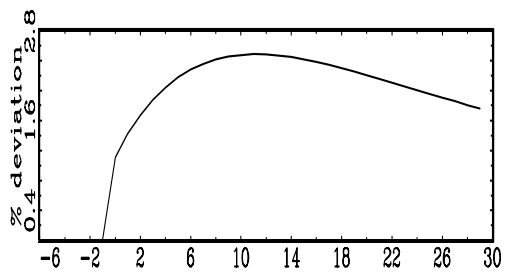

